\title{
REFLEXŌES SOBRE A CONSTRUÇÃO DA IDENTIDADE PROFISSIONAL DE UMA DOCENTE DA EDUCAÇÃO INFANTIL
}

\author{
Jéssica Francine Ferreira da Silva ${ }^{1}$ \\ Ana Paula Gestoso de Souza ${ }^{2}$ \\ Andréia Barboza Braga ${ }^{3}$
}

\section{RESUMO}

Este trabalho, de natureza qualitativa, foi realizado por meio da análise de um memorial de formação. Investigamos a trajetória de formação de uma professora da Educação Infantil, participante de um projeto de extensão. Buscamos analisar e compreender as experiências relatadas em seu memorial de formação e, desse modo, procuramos identificar e observar indícios da construção de sua identidade profissional. O memorial revelou que as experiências que a professora teve, fez e pensou sobre foram altamente significantes para a sua formação profissional e para a construção de sua identidade docente. Nas revelações de indícios que permeiam a construção de sua identidade profissional observamos que dois contextos se destacam: formação docente e prática.

Palavras-chave: Educação Infantil. Identidade Docente. Memoriais de Formação.

\section{REFLECTIONS ON THE CONSTRUCTION OF THE PROFESSIONAL IDENTITY OF AN EARLY CHILDHOOD EDUCATION TEACHER}

\begin{abstract}
The qualitative study reported in this paper aimed at understanding the construction of the professional identity of an Early Childhood Education teacher during her participation in an extension project through the analysis of her formative journal. The journal revealed that her experiences, actions and reflections while in the project were highly significant for her professional education and for the construction of her identity as a teacher. In the identification of elements suggesting the process of construction of her professional identity, two dimensions stood out: teacher education and teaching practice.
\end{abstract}

Keywords: Early Childhood Education. Formative Journal. Teacher Identity.

\footnotetext{
1 Mestrado em Educação. Doutoranda pelo Programa de Pós-Graduação em Educação da Universidade Federal de São Carlos, São Carlos, São Paulo, Brasil. Orcid iD: 0000-0002-8303-

2467. E-mail: jessica_francine17@hotmail.com

2 Doutorado em Educação. Professora da Universidade Federal de São Carlos, São Carlos, São Paulo, Brasil. Orcid iD: 0000-0002-2015-0829. E-mail: anapaula@ufscar.br

${ }_{3}$ Mestrado Profissional em Educação. Professora da Rede Municipal de Ensino de São Carlos, São Carlos, São Paulo, Brasil. Orcid iD: 0000-0003-1232-7708. E-mail: andreinhabraga@gmail.com
} 


\section{REFLEXIONES SOBRE LA CONSTRUCCIÓN DE LA IDENTIDAD PROFESIONAL DE UNA DOCENTE DE LA EDUCACIÓN INFANTIL}

\section{RESUMEN}

Este trabajo, de naturaleza cualitativa, fue realizado por medio del análisis de un memorial de formación. Investigamos la trayectoria profesional de una profesora de la Educación Infantil, participante de un proyecto de extensión. Buscamos analizar y comprender las experiencias relatadas en su memorial de formación y, de ese modo, buscamos identificar y observar indicios de la construcción de su identidad profesional. El memorial reveló que las experiencias que la profesora tuvo, hizo y pensó sobre fueron altamente significantes para su formación profesional y para la construcción de su identidad docente. En las revelaciones de indicios que permean la construcción de su identidad profesional observamos que dos contextos se destacan: formación docente y práctica.

Palabras Clave: Educación Infantil. Identidade Docente. Memoriais de Formación.

\section{INTRODUÇÃO}

Este artigo é originado de uma pesquisa, financiada pela FAPESPi, que apresenta a análise de memoriais de formação de professoras participantes de uma atividade de extensão universitária, voltada para a formação permanente e em serviço de profissionais que atuam na Educação Infantil em diferentes instituições de uma rede municipal do interior do estado de São Paulo.

Neste artigo, investigamos a trajetória profissional de uma das professoras, analisando as experiências relatadas e, desse modo, buscando identificar e compreender indícios da construção de sua identidade profissional.

Na análise, consideramos o processo de aprendizagem da docência como contínuo, ocorrendo ao longo da trajetória de vida do sujeito (NÓVOA, 2000) e fortemente ligado à construção da identidade profissional (TARDIF, 2002). A construção da identidade profissional, por sua vez, é marcada pelo entrecruzamento de uma dimensão individual - "identidade para si" - e de uma dimensão coletiva - "identidade para o outro" - que se desenvolve através das relações externas e é influenciado por múltiplos contextos (DUBAR, 2005). Desse modo, a identidade dos professores é 
construída por inúmeras e variadas fontes de saberes e carregam marcas de caráter pessoal e profissional, configurando-se numa complexa rede de histórias e conhecimentos. Todavia, autores como Tardif e Raymond (2000), por exemplo, destacam que não é possível compreender a identidade dos professores sem considerar suas histórias, pois sua historicidade modela sua identidade profissional e pessoal.

Portanto, consideramos que a narrativa, mais especificamente o memorial de formação, é uma opção válida como instrumento metodológico para a formação de professores, pois configura-se como investigação, por se vincular à produção de conhecimentos experienciais dos docentes em formação, assim como é formação, por partir do princípio que o sujeito toma consciência de si e de suas aprendizagens ao viver e, ao mesmo tempo, dos papéis de ator e investigador da própria história (SOUZA, 2006). Assim, o memorial possibilita um movimento de investigação sobre o processo de formação, bem como o entendimento dos sentimentos e das representações dos sujeitos em seu processo de formação e autoformação (SOUZA, 2006).

\section{APORTES TEÓRICOS}

No Brasil, o atendimento/a educação de crianças de 0 a 6 anos surgiu no século XIX. Autores como Kramer (1995), Kishimoto (1988) e Kuhlmann Jr. (2001) apresentam diferentes fases desse processo, como, por exemplo, a fase da filantropia, que ocorreu durante o período colonial e se caracterizou pelo atendimento de crianças órfãs e abandonadas, e a fase higienista, que aconteceu durante o século XIX e início do século XX e caracterizou-se pela ampliação do atendimento, surgindo os jardins de infância para a classe mais abastada e as creches para as mães trabalhadoras (MARAFON, s/d).

Com a urbanização e o crescimento das cidades, iniciativas isoladas foram instauradas para auxiliar no combate das altas taxas de mortalidade infantil; inaugurando as entidades de amparo. Além disso, devido ao abandono e à exploração das crianças, a necessidade de se pensar em espaços para "guardá-las" era fundamental, por isso surgiram as creches 
com caráter assistencialista (KRAMER, 1987). Junto às creches difundiram-se no Brasil as escolas maternais e os jardins de infância. Todavia, enquanto as creches e as escolas maternais possuíam um viés assistencialista, voltado para as crianças pobres, os jardins de infância possuíam um viés educativo, voltado para as crianças ricas (ROSEMBERG, 2003).

Oliveira (2005) especifica que no início do século XX ocorreram diversos debates em torno do cuidado, da preservação e da preparação da infância, e, junto a isso, aconteceram inúmeras reivindicações partindo de mulheres trabalhadoras, que lutavam por locais onde pudessem deixar seus filhos enquanto estivessem trabalhando. Assim, o atendimento, de caráter assistencialista, de crianças pequenas em espaços coletivos, inicialmente, correspondia a um direito da família que foi conquistado pelas lutas e militâncias das mulheres na época.

As primeiras regulamentações sobre 0 atendimento de crianças pequenas em escolas maternais e jardins de infância, levando em conta a educação, a moral, a higiene e o papel da mulher, tiveram início após o primeiro Congresso Brasileiro de Proteção à Infância (1922). Na década de 1940, as ações governamentais na área de saúde, previdência e assistência se tornaram mais efetivas, tendo em vista que o higienismo, a filantropia e a puericultura dominaram a perspectiva de educação para as crianças pequenas (OLIVEIRA, 2005).

Após esse período, houve uma série de iniciativas que mantiveram o atendimento às crianças em uma perspectiva assistencialista. Apenas com a Constituição de 1988 a responsabilização dessa etapa de ensino se tornou dever do Estado; sendo neste cenário que a Educação Infantil passou a ser vista como o oposto da assistência (KUHLMANN JR., 2001). O Estatuto da Criança e do Adolescente (ECA) também assegurou o direito da criança à educação, a partir da Lei $n^{\circ} 8.069 / 1990$, tendo em vista que o artigo 54 estabelece como dever do Estado assegurar o atendimento em creches e pré-escolas para crianças de 0 a 6 anos de idade (BRASIL, 1990).

Neste contexto, houve uma ampliação expressiva do acesso nas instituições de Educação Infantil, desencadeando mudanças significativas 
no cenário social e educacional, como mencionar a Educação Infantil como a primeira etapa da educação básica na Lei de Diretrizes e Bases da Educação - LDB no 9.394/96 - (KUHLMANN JR., 2001). A partir da promulgação da LDB, artigos como 029,061 e 062 destacam que a finalidade da Educação Infantil deve ser o desenvolvimento integral da criança até seis anos de idade e que os professores dessa etapa de ensino devem ter como formação mínima a oferecida em nível médio ou superior, devendo esta atender às especificidades do exercício de suas atividades.

Desse modo, percebem-se inúmeras mudanças nos papéis das creches e pré-escolas, especialmente na função e formação dos profissionais que atuam nesse nível de ensino (KISHIMOTO, 2002).

Em meio a este contexto, diferentes documentos foram elaborados pelo MEC (Ministério da Educação) para orientar o trabalho na Educação Infantil. Além disso, em 2005 e 2006 foi determinado pelas Leis n 11.114/2005 e 11.274/2006 que a matrícula dos alunos nos anos iniciais do Ensino Fundamental deverá ser aos 6 anos de idade, estabelecendo a duração de nove anos do Ensino Fundamental. A Educação Infantil, então, passou a atender crianças de 0 a 5 anos. Além disso, a Educação Infantil, por meio da Lei $n^{\circ}$ 12.796/2013 (que ajusta a Lei $n^{\circ}$ 9.394/96), também se tornou obrigatória a partir dos 4 anos de idade.

Neste novo cenário, a Educação Infantil passa por um forte processo de revisão sobre as concepções de educação/ensino, e o professor começa a ser visto como uma figura que possui um papel fundamental na formação dessas crianças (KISHIMOTO, 2002). Ademais, as concepções sobre a criança e infância também se alteram, rompendo com a ideia de criança universal que deverá ser preparada para a vida adulta. Essa nova visão concebe a criança como um ator social que produz cultura ao se relacionar com o mundo de diferentes formas, essa cultura se expressa nos pensamentos, nos jogos, nas brincadeiras e nos desenhos das crianças (CORSARO, 1997). Além disso, essa nova visão entende a infância como um construto social (DORNELLES, 2005). Assim, essa autonomia da criança na produção da 
cultura é relativa, uma vez que ocorre na interação com outras crianças e com os adultos dentro de determinados contextos.

O trabalho com crianças pequenas envolve uma gama de múltiplos e importantes aspectos, sendo fundamental, conforme pontua Campos (1999), que o professor de Educação Infantil conheça densamente todas as fases de desenvolvimento, as características e a realidade da qual as crianças partem e o modo como aprendem, buscando estabelecer a educação em sua integralidade, em que o cuidar é indissociável do processo educativo.

Para Ostetto (2008), o professor na Educação Infantil tem como função principal ouvir, observar e registrar as estratégias que a criança utiliza, de tal maneira que seja possível qualificar as experiências por ela vivida e entendêla como protagonista desse processo.

Existe uma grande complexidade que se desdobra em torno do papel de ser professor da Educação Infantil, uma vez que os bebês e as crianças pequenas possuem especificidades e demandas diferentes das crianças maiores, como, por exemplo, a vulnerabilidade e a dependência da família, além de uma gama de linguagens e expressividades que são particulares dessa fase e inerentes aos processos da constituição do ser criança (ROCHA, 2001; BARBOSA, 2010; FOCHI, 2015).

O brincar possui um papel fundamental nesse processo. De acordo com Kishimoto (2001), ao brincar, as crianças pensam sobre a realidade e o meio em que estão inseridas, formando conceitos, selecionando ideias e percepções. Ainda segundo a autora, o brincar auxilia no processo de formação, construção, socialização e potencializa o desenvolvimento de diversas habilidades, afinal, ao brincar, as crianças expõem diversos sentimentos, aprendem, exploram, se movimentam, dentre outros, lidando com dificuldades psicológicas complexas. Importante destacar que em uma visão sociológica, histórica ou antropológica a atividade de brincar não é inata, é aprendida na cultura (BROUGÈRE, 2003).

Assim, o docente na Educação Infantil deve realizar seu trabalho visando permitir que as crianças tenham experiências mais aprofundadas e significativas, centralizando seu trabalho nas provocações de oportunidades 
de descobertas, por meio da estimulação do diálogo e de ação conjunta (EDWARDS, 1999).

Anteriormente, devido ao caráter assistencialista, não se pensava na formação dos sujeitos que iriam atuar na Educação Infantil (ANDRADE, 2010), mas, com as especificações da Lei 9.394/96 - que reconhece a Educação Infantil como parte integrante do sistema educacional e determina medidas para a regulamentação da área no Brasil -, a formação dos profissionais dessa etapa de ensino passou a ser mais discutida, e a própria legislação pontuou a necessidade de uma formação específica para esses profissionais.

Agregado ao caráter assistencialista da Educação Infantil que se manteve fortemente ao longo de sua constituição, durante muito tempo o perfil do professor de Educação Infantil esteve ligado ao modelo idealizado de mulher como naturalmente apta a cuidar e educar as crianças pequenas e à não obrigatoriedade de uma formação específica, o que ainda leva os docentes de Educação Infantil a enfrentarem diversos desafios e dilemas com relação aos elementos que circundam seu trabalho (KRAMER, 2008) e dificulta a construção de uma identidade para esses profissionais (TARDIF, 2002).

A construção da identidade profissional não ocorre apenas no momento de formação inicial, mas ao longo da carreira e trajetória de vida do sujeito (NÓVOA, 1992; TARDIF, 2002; MARCELO, 2009; dentre outros). Assim, a construção da identidade não é um processo pronto e acabado, mas que se modifica ao longo da vida, constituindo o processo de socialização de um sujeito historicamente situado. Autores como Dubar (2005), Berger e Luckmann (1985) assinalam que a identidade é construída dialeticamente entre os sujeitos, sendo influenciada a partir e de acordo com as experiências/realidades que são vivenciadas dentro da sociedade.

Segundo Dubar (2005), a constituição identitária é marcada pelo entrecruzamento de uma dimensão individual - "identidade para si" - que é resultado de uma construção interna e de uma dimensão coletiva "identidade para o outro", desenvolvida através das relações externas a 
partir de categorias que identificam e reconhecem um sujeito em determinado espaço social - "identidade para o outro". Ademais, a identidade biográfica não é preestabelecida, nem ilusória, e não ocupa local secundário diante das determinações sociais; por outro lado, estas categorias sociais não são menos importantes que a dimensão subjetiva.

Nóvoa $(2000,2017)$ também destaca o caráter processual e múltiplo da construção identitária, em suas dimensões individual e coletiva:

Não se trata de definir uma identidade fixa, mas, bem pelo contrário, de compreender as múltiplas identidades que existem numa profissão e, sobretudo, de pensar a construção identitária como um processo. Nesse sentido, ninguém constrói a sua identidade profissional fora de um contexto organizacional e de um posicionamento no seio de um colectivo que the dê sentido e densidade (NÓVOA, 2017, p. 1118).

De forma semelhante, Marcelo (2009, p. 112) pontua o aspecto inacabado da identidade e suas dimensões relacional e contextual:

É preciso entender o conceito de identidade docente como uma realidade que evolui e se desenvolve, tanto pessoal como coletivamente. A identidade não é algo que se possua, mas sim algo que se desenvolve durante a vida. A identidade não é um atributo fixo para uma pessoa, e sim um fenômeno relacional. O desenvolvimento da identidade acontece no terreno do intersubjetivo e se caracteriza como um processo evolutivo, um processo de interpretação de si mesmo como pessoa dentro de um determinado contexto.

Entendemos, portanto, a identidade como inseparável da relação entre indivíduos e sociedade. Desse modo, a identidade dos professores é construída por saberes de fontes variadas, carregando, assim, marcas de caráter pessoal e profissional, configurando-se numa complexa rede de histórias e conhecimentos. Tardif e Raymond (2000) destacam que não é possível compreender a identidade dos professores sem considerar suas histórias, pois sua historicidade modela sua identidade profissional e pessoal. A trajetória pessoal do professor reflete fortemente suas práticas e, ao mesmo tempo, constitui sua identidade. 
As ideias de Gatti (1996) e Ostetto (2008) também assessoram esta discussão, uma vez que as autoras enfatizam que a identidade do professor é a maneira única de ser e estar no mundo e no trabalho, pressupondo caminhos de autoconhecimento cerceados por elementos multideterminantes para a construção da identidade profissional dos profissionais da educação.

No percurso de constituição da identidade profissional se entrecruzam momentos marcantes que podem propiciar reflexões, despertar um novo olhar sobre determinado fenômeno ou sobre a própria trajetória docente, acarretar mudanças de concepções e consequentemente de tomadas de decisões, gerando aprendizagens, ressignificação e/ou afirmação da identidade docente (JOSSO, 2010).

Partilhando dessas premissas sobre a identidade docente, é importante que o professor reflita sobre a docência e sobre seu ofício para conhecer a si mesmo, em um processo de autorreflexão (JOSSO, 2004), e as narrativas são uma forma de auxiliá-los nesse processo. As narrativas potencializam e dão visibilidade aos aspectos da identidade profissional.

Ao narrar as histórias sobre o seu próprio percurso de vida e/ou trajetória de formação, o professor faz mais do que registrar esses acontecimentos; ele altera suas formas de pensar e agir, podendo motivarse para modificar suas práticas e manter uma atitude reflexiva e crítica sobre o seu próprio desempenho docente (REIS, 2008). Segundo Reis (2008, p. 4), através das narrativas

[os professores] explicitam os conhecimentos pedagógicos construídos através das suas experiências, permitindo a sua análise, discussão e eventual reformulação. A redacção de relatos sobre as suas experiências pedagógicas constitui, por si só, um forte processo de desenvolvimento pessoal e profissional ao desencadear, entre outros aspectos: a) o questionamento das suas competências e das suas acções; b) a tomada de consciência do que sabem e do que necessitam de aprender; c) o desejo de mudança; e d) o estabelecimento de compromissos e a definição de metas a atingir. 
As narrativas também podem revelar experiências formadoras. Para qualificar uma experiência enquanto formadora, "é necessário falarmos sob - ângulo da aprendizagem, essa experiência simboliza atitudes, comportamentos, pensamentos, saber-fazer, sentimentos que caracterizam uma subjetividade e identidades" (JOSSO, 2004, p. 47-48).

Para compreender a construção da experiência, Josso (2004) enfoca três modalidades de elaboração: "ter experiências": vivências de acontecimentos que ocorreram durante a vida e se tornaram significativos, mas não foram provocadas pelo sujeito; "fazer experiência": são as vivências que o próprio sujeito provoca, de propósito, para fazer experiências; "pensar sobre as experiências": implica nos momentos em que o sujeito se coloca em movimento para pensar sobre as experiências que teve sem procurá-las, e aquelas que ele mesmo criou.

Assim, por meio de narrativas, os professores podem (re)construir e (res)significar as suas próprias experiências de ensino e aprendizagem e as suas próprias trajetórias de formação. A narrativa potencializa um processo de reflexão pedagógica que permite aos professores compreenderem suas ações e a ocorrência de determinados acontecimentos, de modo a poderem criar (se assim pertinente for) novas estratégias a partir de um processo de reflexão, ação e nova reflexão. Portanto, a narrativa de suas histórias pode propiciar reflexões e o compartilhamento de experiências importantes para a constituição da identidade docente e para $O$ desenvolvimento profissional (SOUZA, 2006).

\section{PROCEDIMENTOS METODOLÓGICOS}

Para o levantamento de dados, optamos pela narrativa, mais especificamente pelos memoriais de formação. Por meio de uma abordagem qualitativa, consideramos que os textos narrativos são instrumentos de ensino/formação e de pesquisa (SOUZA, 2006).

Como instrumento de pesquisa os textos narrativos auxiliam a identificar, compreender e analisar como se dá 0 processo de 
conhecimento através da investigação. Neste sentido, Souza (2006, p. 26) destaca que essa perspectiva de trabalho

[...] configura-se como investigação porque se vincula à produção de conhecimentos experienciais dos sujeitos adultos em formação. Por outro lado, é formação porque parte do princípio de que o sujeito toma consciência de si e de suas aprendizagens experienciais quando vive, simultaneamente, os papéis de ator e investigador da sua própria história.

Além disso, o autor infere que a narrativa é uma opção de instrumento metodológico para a formação de professores, pois

[...] possibilita inicialmente um movimento de investigação sobre o processo de formação e, por outro lado, possibilita, a partir das narrativas (auto) biográficas, entender os sentimentos e representações dos atores sociais no seu processo de formação e autoformação (SOUZA, 2006, p. 34).

Contudo, esse discurso não se desvencilha dos problemas referentes à veracidade ou fidedignidade dos fatos. Mas esse elemento não retira as potencialidades das narrativas no âmbito da pesquisa, uma vez que estas se configuram como um instrumento ideal para analisar histórias de professores, pois oferecem meios para ouvir suas vozes e começar a entender sua cultura de seu ponto de vista; chamando a atenção para as dimensões essenciais da vida ao tornar-se professor (CUNHA, 1997).

Inferimos que o trabalho com narrativas não busca estabelecer generalizações estatísticas, mas compreender o fenômeno em estudo. Portanto, como pontua Abrahão (2003, p.80):

Ao trabalhar com metodologia e fontes dessa natureza [narrativa] o pesquisador conscientemente adota uma tradição em pesquisa que reconhece ser a realidade social multifacetária, socialmente construída por seres humanos que vivenciam a experiência de modo holístico e integrado, em que as pessoas estão em constante processo de autoconhecimento. Por esta razão, sabe-se, desde o início, trabalhando antes com emoções e intuições do que com dados exatos e acabados; com subjetividades, portanto, antes do que com o objetivo. Nesta tradição de pesquisa, o pesquisador não pretende estabelecer generalizações 
estatísticas, mas, sim, compreender o fenômeno em estudo, o que lhe pode até permitir uma generalização analítica.

Em nossa pesquisa, optamos pelo memorial como objeto de estudo por considerá-lo um gênero discursivo, dentre outros, que possibilita que os sujeitos "documentem o que fazem, o que pensam, o que pensam sobre o que fazem, assim como suas inquietações, dificuldades, conquistas, sua produção intelectual" (PRADO; FERREIRA; FERNANDES, 2011, p. 145). Esse gênero discursivo implica que o narrador, sujeito da narração, evoque suas memórias e as apresente considerando determinado tempo-espaço, e nesse processo tomará decisões e fará escolhas. Ademais, utilizamos o termo memorial de formação considerando as ideias de Abrahão (2011). Para a autora, o conceito de memorial de formação é

o processo e a resultante da rememoração com reflexão sobre fatos relatados, oralmente e/ou por escrito, mediante uma narrativa de vida, cuja trama (enredo) faça sentido para o sujeito da narração, com a intenção, desde que haja sempre uma intencionalidade, de clarificar e ressignificar aspectos, dimensões e momentos da própria formação. No que respeita ao processo, trata-se de experienciar o momento da narrativa reflexionada também como um componente formativo essencial. Trata-se de o narrador, elaborador do próprio memorial, ser realmente o sujeito da narração (embora dela também seja objeto), consciente de que a reflexão empreendida é elemento sinequa non para a compreensão da própria formação e, ainda, de que o momento da narração, nos moldes aqui entendidos, é, também ele, momento formativo (ABRAHÃO, 2011, p. 165).

Considerando essas premissas, a proposta da pesquisa foi que as professoras de Educação Infantilii, participantes da atividade de extensão, elaborassem memoriais de formação.

Inicialmente, apresentamos a pesquisa às professorasiii e formamos com elas um grupo de estudo e discussão sobre os memoriais de formação. Após este trabalho, as professoras deram início à escrita de seus memoriais considerando os seguintes elementos: 1) Da Educação Infantil ao Ensino Médio; 2) Formação profissional: motivos e influências para a escolha 
profissional; 3) A atuação profissional: do início da docência ao momento atual.

Durante o processo da análise inicial dos memoriais, realizamos rodas de conversa com as professoras nas quais compartilhávamos os eixos de análise que havíamos identificado na primeira leitura dos memoriais. Fizemos a leitura dos memoriais na perspectiva da análise de prosa (ANDRÉ, 1984), buscando olhar as narrativas de forma mais abrangente e flexível, assim organizamos os dados em tópicos e temas, que foram elaborados e reelaborados durante o processo de análise. Ademais, as rodas de conversa foram importantes para que as professoras dialogassem sobre suas narrativas e nos possibilitou a confirmação de eixos de análises e, em alguns casos, a definição de outros.

Conforme pontuado anteriormente, neste artigo, investigamos a trajetória profissional de uma das professoras, buscando analisar suas experiências relatadas no memorial e, assim, identificar e compreender indícios da construção de sua identidade profissional.

Para a análise dos dados, estabeleceu-se uma parceria com a professora autora do memorial, que também se tornou uma das autoras deste artigo. Essa parceria entre pesquisadores acadêmicos e professor da escola implica em considerar que cada parceiro no processo de investigação contribui com conhecimentos específicos e importantes e que a relação entre eles é multifacetada e não é tão hierárquica (COLE; KNOWLES, 1993).

As pesquisadoras dialogaram com a professora, explicando claramente as expectativas e os papéis de cada uma, tiveram o compromisso com uma postura não avaliadora e, assim, buscou-se estabelecer uma relação na qual a professora se sentisse à vontade e valorizada. Ela foi receptiva à parceira e compreendeu a contribuição desse processo para o seu desenvolvimento profissional. Assim, a pré-análise dos dados feita pelas pesquisadoras foi encaminhada para a professora autora do memorial, que contribuiu para a ampliação das análises oferecendo 
outro olhar para sua narrativa. Criou-se um movimento de troca de reflexões, garantindo a representação da voz da professora.

\section{REVELAÇÕES DO MEMORIAL}

\section{Memórias da educação infantil ao ensino médio}

Ao analisar o memorial de uma professora de Educação Infantil, é oportuno retomar Josso (2004), quando pontua que passamos a ter experiências somente a partir do exercício de reflexão sobre as nossas vivências, do contrário, o que teremos serão apenas vivências e não experiências. Dessa forma,

[...] falar das próprias experiências formadoras é, pois, de certa maneira, contar de si mesmo, a própria história, as suas qualidades pessoais e socioculturais, o valor que se atribui ao que é 'vivido', na continuidade temporal do nosso ser psicossomático (JOSSO, 2004, p. 48).

Sendo assim, através de suas narrativas, a autora do memorial revela saberes construídos na experiência vivida; sendo esses saberes fundamentais à formação e construção de sua identidade docente.

A professora começa seu memorial relatando que iniciou sua fase de escolarização com 4 anos de idade. Sobre as lembranças na pré-escola, recorda-se dos brinquedos no parquinho e das peraltices que fazia, como se pendurar de cabeça para baixo nas argolas do parque (daquelas parecidas com as de circo).

Ao narrar sobre os brinquedos de seu tempo de pré-escola, destaca ainda que não se lembra de ver alguma criança se machucar gravemente naqueles brinquedos e que, hoje em dia, as crianças são privadas dessas brincadeiras que "demandam desenvolvimento de destrezas e equilíbrio", por isso "as crianças mal conseguem correr sem cair".

A professora também se lembra de algumas datas específicas, comemoradas na pré-escola, como o dia do índio. Se recorda de fazer saia e cocar com papel, colar com macarrão e pintar o rosto com tinta. Ao se referir a esse episódio, pontua: 
Obs: hoje como professora eu vou contra a esses tipos de abordagem que só cria estereótipos ou em outros casos se fomenta o consumismo e a geração de lixo (professora, memorial de formação, 2017).

Com relação ao Ensino Fundamental, a professora revela ter participado de atividades culturais e de reciclagem:

Quando eu estava na Oitava série teve um grande evento na escola, uma grande gincana de coleta de materiais recicláveis, onde cada classe poderia trazer materiais recicláveis para a escola, tudo era pesado, contabilizado e anotado, assim juntava-se pontos durante meses e meses (professora, memorial de formação, 2017).

Lembro que nesta época [Ensino Fundamental] íamos muito a eventos no teatro municipal, que fica a poucos quarteirões da minha escola. Lá víamos peças de teatro e certa vez o pessoal do teatro foi até a escola divulgar que estavam abrindo turmas para iniciantes. Eu fui me inscrever junto com algumas amigas e conhecidos da escola, foi muito importante para mim essa época (professora, memorial de formação, 2017).

Já ao narrar sobre o Ensino Médio, destaca que não se lembra muito dessa época, a não ser das aulas de Geografia e sobre como essas aulas deixaram marcas até hoje com relação aos aprendizados sobre clima, relevo e a importância da policultura.

Observamos que durante a trajetória de escolarização da professora, da Educação Infantil ao Ensino Médio, as experiências acerca de festividades (datas comemorativas), atividades, brincadeiras, programas culturais e ambientais se apresentaram fortemente como constituintes de sua identidade como docente da Educação Infantil. Afinal, em sua prática docente, ela destaca o quanto leva em consideração todas essas questões, realizando diferentes atividades com instrumentos musicais e materiais diversificados, valorizando as diferentes culturas, evitando fazer uso de materiais que agridam ao meio ambiente e buscando aproveitar ao máximo os espaços abertos e mais próximos da natureza. Um fato interessante de seu memorial é que a professora também compartilhou imagens de suas 
atividades com as crianças/os bebês e essas imagens também revelam tais indícios de sua prática. Observamos, então, como a "identidade para si" (DUBAR, 2005) vai sendo construída a partir das experiências de escolarização, evidenciando a força do processo de "aprendizagem por observação" descrito por Lortie (1975) e da trajetória pessoal na construção da identidade profissional (TARDIF; RAYMOND, 2000). Essas experiências foram ressignificadas pela professora em um processo de pensar sobre elas (JOSSO, 2004), em alguns casos a professora se posiciona contra práticas escolares que vivenciou, como as baseadas em datas comemorativas, em outros ela conecta sua prática docente à saberes construídos em sua escolarização.

\section{Memórias da formação profissional}

Ao rememorar suas experiências de formação profissional, a professora narra que não imaginava que poderia se tornar docente ou até mesmo estudar em alguma universidade. Assim, após a influência de sua família para que ingressasse no ensino superior, ela prestou vestibular para Pedagogia, por considerar que era um dos cursos "mais fáceis de entrar".

Em seu terceiro ano, iniciou um estágio na creche da universidade e considera que sua "atuação como professora ocorreu juntamente com [sua] formação inicial", uma vez que "logo no primeiro dia [do estágio, foi] comunicada que assumiria uma vaga de 'professora titular' de uma turma de berçário", contudo em nenhum momento ela esteve sozinha com as criançaiv.

Para a professora, as experiências neste estágio proporcionaram inúmeros ganhos de cunho pessoal e profissional, pois ela considera ter tido a oportunidade de conhecer e trabalhar junto às profissionais engajados com a Educação Infantil, que valorizam a atuação com os bebês e crianças pequenas (e são valorizados por isso dentro daquele contexto), se preocupam com o espaço físico e buscam proporcionar um atendimento de qualidade, a partir de práticas específicas e adequadas. Assim, a 
professora pontua que foi "aprendendo a ser educadora de bebê e do que é importante para eles" durante este estágio.

A partir dessa experiência positiva, ela estabeleceu grande afinidade com a Educação Infantil, destacando que essa etapa de ensino foi sua "paixão durante a graduação". Essa afinidade se mostra ainda mais latente ao narrar que, logo após concluir a graduação, se matriculou em uma especialização em Educação Infantil.

Contudo, ao contrário dessas experiências durante o estágio na Educação Infantil, ao narrar sobre suas vivências no estágio do Ensino Fundamental, a autora do memorial revela que "foram um pouco traumáticas". Ela destaca que teve problemas para lidar com crianças maiores e que não se sentia preparada para trabalhar com os conteúdos dessa etapa da educação.

Além dessas experiências no estágio, a professora também rememora que na graduação teve a oportunidade de trabalhar com compostagem e educação ambiental, além de ter aprendido várias músicas e brincadeiras para fazer com as crianças.

Nesse processo de se constituir como professora, as experiências de estágios na formação inicial da autora do memorial se configuraram como fundamentais para sua escolha docente. As experiências consideradas por ela negativas, vividas em seu estágio no Ensino Fundamental, reveleram marcas profundas em sua identidade docente, uma vez que ela relata que "nunca [irá] prestar concurso para trabalhar" nesta etapa de ensino devido às experiências dessa época.

Por outro lado, as experiências positivas com a Educação Infantil, também no estágio, fortaleceram e definiram sua escolha pela carreira, além de propiciarem a construção de concepções e ideais em torno do ser e fazer docente nesta etapa de ensino, sobretudo com relação à atuação com bebês. Assim, indo ao encontro do que pontua La Roca (2012) com relação à formação docente na Educação Infantil, essas experiências da professora evidenciam o início da construção de uma concepção sobre essa etapa de ensino que assume uma reflexão sobre a prática sem partir de 
concepções pré-determinadas e atenta aos diversos sujeitos do processo docente; superando marcas do caráter assistencialista na Educação Infantil (ANDRADE, 2010). Além disso, a professora também demonstra pensar em práticas específicas para a atuação com bebês, evidenciando a construção de um saber característico da docência na Educação Infantil, como evidencia Barbosa (2010), Rocha (2011), Fochi (2015), dentre outros. Posteriormente, a sua trajetória profissional revela que essas concepções vão ganhando força.

\section{Memórias da atuação profissional}

Conforme pontuado anteriormente, durante sua formação inicial, a narradora vivenciou práticas diferenciadas na creche da universidade que leva para sua atuação profissional. Podemos fazer um paralelo com Flores (2015), ao pontuar que o contexto no qual ocorre o processo de aprender a ensinar e a formação inicial pode influenciar na constituição da identidade profissional.

Entretanto, o início da docência da professora é marcado pela inserção em um contexto profissional diferente daquele vivenciado no estágio na creche da unviversidade, destacando que no início de sua atuação profissional sofreu um choque de realidade, encontrando um cenário diferente do que esperava:

Quando comecei a dar aulas já como professora mesmo, levei um choque de realidade. Encontrei salas de aulas lotadas, crianças agitadas, gritando, se empurrando, brigando por espaços e atenção. Estrutura de escolas municipais frias e sem muito atrativo pedagógico (professora, memorial de formação, 2017).

Mas esse choque, não imobilizou a professora. Ao narrar suas experiências na atuação profissional, evidenciamos que ser professor vai além de se apropriar de conhecimentos profissionais referentes à Educação Infantil, ratificando o exposto por Tancredi (2009, p. 16) ao pontuar que tornar-se professor "envolve assumir as responsabilidades que emergem da 
prática profissional numa determinada instituição educativa, ou seja, comprometer-se com uma escola e seu contexto". Para a autora, ser professor é não se acomodar, é buscar caminhos que propiciem a superação das dificuldades enfrentadas cotidianamente pelos alunos, professores e escolas.

Outra tensão narrada pela professora e que possivelmente marca a constituição de sua identidade é a questão da divisão de salas com outras professoras. Ela considera esse fator bastante delicado, uma vez que nem sempre as professoras compartilham dos mesmos ideais e interesses:

Já como professora de bebês algumas coisas mudam, trabalhamos com diferentes pares na mesma sala, em minha caminhada aqui percebo que a grande maioria das professoras que atuam em berçário não buscam, ou não acreditam existir muitas possibilidades de atuação com bebês. [...] O que se vê é a mesma coisa, mesmas atividades ou falta delas. Uma tristeza para mim (professora, memorial de formação, 2017).

Observamos que a professora se coloca contra as características que um coletivo atribui à docência com bebês, não levando em consideração suas especificidades e tampouco os reconhecendo como seres ativos e interativos (capazes de se relacionar com objetos e pessoas), que apresentam diversas possibilidades de atuação. Consideramos que essas práticas, que não visualizam as potencialidades da atuação com bebês, possivelmente estão marcadas pelo contexto histórico da Educação Infantil, no qual $O$ atendimento de bebês, principalmente, era fortemente caracterizado pelo assistencialismo, pautado no cuidado, proteção, bemestar e zelo. Assim, a dificuldade de estabelecer uma identidade para a Educação Infantil (KRAMER, 2008) resulta em tensões na constituição da identidade docente que atua nesse nível de ensino.

É fato que os bebês são dependentes em relação ao adulto no que tange ao cuidado - higiene, limpeza e saúde. Todavia, é fundamental que os docentes que atuam na Educação Infantil tenham conhecimento sobre as especificidades da docência dessa etapa de ensino, articulando o 
cuidar, o educar e o brincar e considerando o bebê (e a criança pequena) como um todo, suas características e demandas (CAMPOS, 1999; dentre outros). Assim, é importante que os professores se atentem às linguagens dos bebês, que é expressiva e ocorre através de gestos, olhares, sorrisos, choros, toques, dentre outros, e antecede a linguagem oral. Além disso, o trabalho com bebês não implica na aplicação de um projeto pedagógico objetivo, mas sim no docente se colocar física e emocionalmente à disposição deles, de modo a "escutar as suas vozes" e a acompanhar e observar os seus corpos e suas singularidades (BARBOSA, 2010). Essas características do trabalho com crianças pequenas demandam do professor uma diversidade de tarefas, ampliando o papel desse profissional comparando-o com a atuação em outros níveis de ensino.

A dificuldade em trabalhar com outras docentes na mesma sala, acabou influenciando nas escolhas da professora. Em seu segundo e terceiro ano de docência, ela teve a oportunidade de trabalhar com crianças maiores e relata que foi "sem dúvida um dos melhores anos como professora", pois trabalhou sozinha e se sentiu livre para pôr em prática o que queria fazer. Identificamos uma contradição da realidade vivida. A experiência relatada possibilitou à docente reforçar sua ideia sobre ser professora de bebês, professor que busca articular o cuidar com o educar e brincar, compreende que os bebês são vulneráveis, mas também aprendem, e que essas aprendizagens Ihes são fundamentais, evidenciando seu compromisso profissional. Por outro lado, a experiência vivida propiciou, de certa forma, o aumento do isolamento docente tão criticado por diversos autores, como Lortie (1975), e a fez não ser professora de bebês nos dois anos seguintes. Isso não significa que ela deixou de lado sua convicção sobre as especificidades do trabalho com bebês, inferimos que essa escolha pode ser momentânea e pode ser caracterizada como uma prática de sobrevivência (HURBERMAN, 1999) em seu início da docência.

Também observamos um conflito pessoal da professora, ao destacar que, às vezes, não tem paciência no trabalho e, em razão disso, coloca em dúvida sua profissão, porém se considera uma boa professora, por estar 
sempre se questionando e se envolver intensamente com seu trabalho. Neste sentido, relata que:

Procuro ler e reler documentos oficiais como diretrizes, parâmetros, literatura de práticas em educação infantil e procuro sempre inspiração para temas de aulas [...] (professora, memorial de formação, 2017).

Esse conflito pessoal coloca a professora em um movimento de fazer experiência (JOSSO, 2004), ao buscar seu próprio desenvolvimento profissional, afinal, ela relatou participar de atividades de extensão, grupos de pesquisa e estudar documentos oficiais e obras diversas acerca do tema da Educação Infantil e prática docente. É oportuno retomar Nóvoa (1992, p. 25), ao sinalizar que a formação docente se constrói "através de um trabalho de reflexividade crítica sobre as práticas", uma vez que nos parece que a narradora mostra essa reflexividade crítica e se assume como protagonista de seu desenvolvimento profissional.

Em outros momentos do memorial, a professora também enfatiza que carrega em sua prática as contribuições da formação inicial e de formações continuadas e que sua atuação engloba um pouco do que aprendeu (na graduação e em cursos de especialização) e vem aprendendo (em atividades de extensão e grupos de pesquisa).

Em suma, a trajetória de formação e de atuação da professora se revelou como constituinte da sua identidade profissional, de seu ser e fazer docente, bem como do seu olhar para a Educação Infantil. Reiteramos que as suas experiências são formadoras (JOSSO, 2004) e que ao longo de sua trajetória de vida ela continuará definindo a si mesma, às vezes em meio a conflitos e negociações e outras em meio a descobertas e aprendizagens. Definição que ocorre na dimensão individual e coletiva e que evidencia as (res)significações de sua identidade; conforme o exposto por Nóvoa (1992), Tardif (2002), Dubar (2005), dentre outros.

O exposto na narrativa da professora revela um processo de construção da identidade docente inseparável da relação entre indivíduos e 
sociedade, mostrando que a trajetória de formação (do início da escolaridade ao momento atual) e as histórias de vida influenciam fortemente nessa construção. Assim, a construção da identidade docente da professora está diretamente relacionada às vivências e experiências do professor, tanto no âmbito pessoal quanto no âmbito profissional, estando a identidade profissional e a identidade pessoal interligadas e conexas. Essas considerações convergem com estudos de Dubar (2005), Berger e Luckmann (1985), Tardif e Raymond (2000), dentre outros.

\section{QUE RECADOS O MEMORIAL DA PROFESSORA NOS DEIXA?}

De modo geral, este estudo revelou o quanto a trajetória de vida e de formação influenciam fortemente na construção da identidade docente. Identidade essa que não é estática e não se encerra em determinados momentos da vida ou da carreira, mas é permanente e contínua.

Além do mais, observamos que a trajetória de formação da professora revelou indícios da construção de sua identidade profissional como docente na Educação Infantil. As experiências que ela teve, fez e pensou sobre (JOSSO, 2004) foram altamente significantes para a sua formação profissional e para a construção de sua identidade docente.

Diante disso, o memorial da professora revela que algumas experiências negativas, nos estágios, por vezes acabam não sendo foco de atenção na formação inicial. Do mesmo modo, as experiências positivas que a professora teve acerca da Educação Infantil, também no estágio, que fomentaram reflexões e a construção de uma identidade docente contrária ao contexto histórico de assistencialismo que marcou e ainda marca $o$ cenário da Educação Infantil no Brasil (ANDRADE, 2010), em alguns casos são pouco vivenciadas na formação inicial - levando em consideração a própria narrativa da professora, quando ela relata dificuldade para trabalhar com outras professoras que não visualizam possibilidades de atuação na Educação Infantil.

Inferimos, também, que a realidade que a autora do memorial encontra quando principia sua atuação docente é um dos fatores que a 
mobiliza a pensar sobre suas experiências na formação inicial e concepções construídas sobre a Educação Infantil, e, assim, ela se coloca na contramão da realidade que encontrou. Neste sentido, ela questiona a falta de atuação em conjunto de professoras que não consideram a Educação Infantil como um espaço importante e fundamental de atuação e a importância de uma formação continuada, não se acomodando à situação que encontrou.

Portanto, nas revelações de indícios que permeiam a construção de identidade professional da professora, observamos que dois contextos se destacam: formação docente e prática. Na formação docente, a professora construiu concepções de infância, de criança e de Educação Infantil. Durante sua prática, a professora se colocou em um movimento de pensar sobre suas concepções e a realidade que encontrou e, desse modo, buscou ser uma docente diferente do que essa realidade the mostrava. Assim, as experiências da professora e as marcas de sua trajetória pessoal e profissional na constrituição de sua identidade docente reforçam algumas certezas, deixando alguns recados, como, por exemplo:

- A necessidade de discutir, na formação inicial, de forma ética e respeitosa as experiências de estágio consideradas negativas pelos licenciandos;

- A urgência de propiciar, na formação inicial e continuada, experiências, no sentido de Josso (2004), i) que focalizem a atuação docente na Educação Infantil que rompa com uma falta de percepção sobre o caráter educativo e formativo dessa etapa de ensino, ii) que propiciem que o professor se mobilize para assumir responsabilidades diante da situação que encontra e se comprometa com a escola e seu contexto e iii) que propiciem o aprender juntos, ou seja, deixar o individualismo, que marca a profissão docente, e "olhar" para o outro e aprender com ele, construindo juntos formas de lidar com as demandas da prática.

\section{REFERÊNCIAS}


ABRAHÃO, M. H. M. B. Memória, narrativas e pesquisa autobiográfica. História da Educação, ASPHE/FaE/UFPel, Pelotas, n.14, p.79-95, set. 2003.

ABRAHÃO, M. H. M. B. Memoriais de formação: a (re)significação das imagens- lembranças/recordações-referências para a pedagoga em formação. Educação. Porto Alegre, v. 34, n. 2, p. 165-172, maio/ago. 2011.

ANDRADE, L. B. P. de. Educação infantil: discurso, legislação e práticas institucionais. São Paulo: Editora UNESP; São Paulo: Cultura Acadêmica, 2010.

ANDRÉ, M. E. D. A. de. Estudo de caso: seu potencial na educação.

Cadernos de Pesquisa, (49):51-54, maio/1984.

BARBOSA, M. C. Especificidades da ação pedagógica com os bebês. Anais do I Seminário Nacional: Currículo em Movimento - Perspectivas Atuais. Belo Horizonte, novembro de 2010.

BERGER, P. L.; LUCKMANN, T. A construção social da realidade: tratado de sociologia do conhecimento. Petrópolis: Editora Vozes, 1985.

BOLÍVAR, A.; DOMINGO, J.; FERNÁNDEZ, M. La Investigación biográficonarrativa en educación: enfoque y metodología. Madrid. La Muralla. 2001.

BRASIL. Diretrizes Curriculares Nacionais para a Educação Infantil. Brasília: MEC/SEB, 2010. Disponível em: http://portal.mec.gov.br/docman/julho-2013pdf/13677-diretrizes-educacao-basica-2013-pdf/file. Acesso em 15 jan. 2019.

BRASIL. Estatuto da Criança e do Adolescente. Lei n 8.069, de 13 de junho de 1990. Disponível em: http://www.planalto.gov.br/ccivil_03/LEIS/L8069.htm. Acesso em 15 jan. 2019.

BRASIL. Lei $n^{\circ} 11.114$, de 16 de maio de 2005. Altera os artigos 6, 30, 32 e 87 da Lei $n^{\circ}$ 9.394, de 20 de Dezembro de 1996, com o objetivo de tornar obrigatório o início do ensino fundamental aos 6 (seis) anos de idade. Diário Oficial da União, Brasília, DF, 17 maio 2005a. Disponível em: http://www.planalto.gov.br/ccivil_03/_Ato2004-2006/2005/Lei/L1 $1114 . \mathrm{htm}$. Acesso em 15 jan. 2019.

BRASIL. Lei $n^{\circ} 11.274,6$ de fevereiro de 2006. Altera a redação dos arts. 29, 30, 32 e 87 da Lei $n^{\circ}$ 9.394, de 20 de dezembro de 1996, que estabelece as diretrizes e bases da educação nacional, dispondo sobre a duração de 9 (nove) anos para o ensino fundamental, com matrícula obrigatória a partir dos 6 (seis) anos de idade. Diário Oficial da União, Brasília, DF, 7 fev. 2006 a. Disponível em: http://www.planalto.gov.br/ccivil_03/_Ato20042006/2006/Lei/L 1 1274.htm. Acesso em 15 jan. 2019. 
BRASIL. Lei de Diretrizes e Bases da Educação. Lei n 9394 de 20 de dezembro de 1996, Brasília. Disponível em:

https://www2.senado.leg.br/bdsf/bitstream/handle/id/70320/65.pdf. Acesso em 17 jan. 2019.

BRASIL. Lei de diretrizes e Bases da Educação. Lei n 12.796 de 04 de abril de 2013. Disponível em: http://www.planalto.gov.br/ccivil_03/_Ato20112014/2013/Lei/L12796.htm. Acesso em 17 jan. 2019.

BROUGÈRE, G. Jogo e educação. Porto Alegre: Artmed, 2003.

CAMPOS, M. M. A formação de professores para crianças de 0 a 6 anos: modelos em debate. Revista Educação \& Sociedade, Campinas, n. 68, p. 126-142, 1999.

COLE, A. L.; KNOWLES, J. G. Teacher Development Partnership Research: A Focus on Methods and Issues. American Educational Research Journal Fall, $v$. 30, n. 3, p.473- 495, 1993.

CORSARO, W. A. The Sociology of Childhood. California: Pine Forge Press, 1997.

CUNHA, M. I. da. Conta-me agora!: as narrativas como alternativas pedagógicas na pesquisa e no ensino. Revista da Faculdade de Educação, FE/USP, São Paulo, v. 23, n. 1-2, jan./dez., 1997.

DUBAR, C. A socialização: construção das identidades sociais e profissionais. São Paulo: Editora Martins Fontes, 2005.

DORNELLES, L. V. Infâncias que nos escapam: da criança na rua à criança cyber. Petrópolis/RJ: Vozes, 2005.

EDWARDS, C. Parceiro, promotor de crescimento e guia - os papéis dos professores de Reggio em ação. In: EDWARDS, C.; GANDINI, L.; FORMAN, G. As cem linguagens da criança. A abordagem de Reggio Emilia na Educação da primeira infância. Porto Alegre: Artes Médicas, 1999.

FOCHI, P. Afinal, o que os bebês fazem no berçário? Comunicação, autonomia e saber-fazer de bebês em um contexto de vida coletiva. Penso Editora, 2015.

FLORES, M. A. Formação docente e identidade profissional: tensões e (des)continuidades. Educação (Porto Alegre, impresso), v. 38, n. 1, p. 138-146, jan.-abr. 2015.

GATTI, B. A. Os professores e suas identidades: o desvelamento da heterogeneidade. Cadernos de Pesquisa. N. 98, 1996. 
HUBERMAN, M. O ciclo de vida profissional dos professores. In: NÓVOA, A. (Org.). Vidas de professores. 2 ed. Portugal: Porto Editora, 1995, p. 31-61

JOSSO, M-C. Experiências de vida e formação. São Paulo: Cortez, 2004.

JOSSO, M-C. Caminhar para si. Tradução Albino Pozzer; Coord: Maria Helena Menna Barreto Abrahão. Porto Alegre: Edipucrs, 2010.

KISHIMOTO, T. M. A pré-escola em São Paulo. São Paulo: Loyola, 1988.

KISHIMOTO, T. M. (Org.). Jogo, brinquedo, brincadeira e a educação. 5. ed. São Paulo: Cortez, 2001.

KISHIMOTO, T. M. Avanços e retrocessos na formação dos profissionais de educação infantil. In: MACHADO, M. L. de A. (Org.). Encontros e desencontros em educação infantil. São Paulo: Cortez, p. 107-115, 2002.

KULHMANN JR., M. Infância e educação infantil: uma abordagem histórica. Porto Alegre: Mediações, 2001.

KRAMER, S. Com a pré-escola nas mãos. São Paulo: Ática, 1987.

KRAMER. S. A política do pré-escolar no Brasil: a arte do disfarce. Rio de Janeiro: Achime, 1995.

KRAMER, S. (Org.). Profissionais de educação infantil: gestão e formação. São Paulo: Ática, 2008.

LA ROCA, M. E. C. de. A formação do professor de educação infantil: interfaces luso-brasileiras. $35^{a}$ Reunião Anual da Anped. Porto de Galinhas/PE. Anais GT08 - Formação de professores. 21 a 24 de outubro de 2012.

LORTIE, D. C. School-teacher: A sociological study. Chicago: University of Chicago Press, 1975.

MARAFON, D. Educação Infantil no Brasil: um percurso histórico entre as idéias e as políticas públicas para a infância. PUC-PR/FATEB. s/d.

MARCELO, C. A identidade docente: constantes e desafios. Revista Brasileira de Pesquisa sobre Formação Docente. Belo Horizonte, n. 1, v. 1, p. 109-131, ago/dez, 2009.

NÓVOA, A. (Org.) Os professores e sua formação. Lisboa: Dom Quixote, 1992. NÓVOA, A. (org.). Vidas de professores. 2a ed. Porto: Porto Editora, 2000. 
NÓVOA, A.; VIEIRA, P. Um alfabeto da formação de professores. Crítica

Educativa, n. 2, v. 3, p. 21 - 49, set./ 2017.

OLIVEIRA. Z. M. R. de. Educação infantil: fundamentos e métodos. São Paulo: Cortez, 2005.

OSTETTO, L. E. Educação Infantil: Saberes e fazeres da formação de professores. Campinas, SP: Papirus, 2008.

PRADO, G. do V. T.; FERREIRA, C. R.; FERNANDES, C. H. Narrativa Pedagógica e Memoriais de Formação: Escrita dos Profissionais da Educação? Revista Teias, v. 12, n. 26, p.143-153, set/dez. 2011.

REIS, P. R. dos. As narrativas na formação de professores e na investigação em educação. Nuances: estudos sobre Educação. Presidente Prudente, SP, ano XIV, v.15, n.16, p. 17-34, jan./dez. 2008.

ROCHA, E. A. C. A pedagogia e a educação infantil. Rev. Bras. Educ., Rio de Janeiro, n. 16, p. 27-34, Apr. 2001.

ROSEMBERG, F. Sísifo e a educação infantil brasileira. Pró-Posições. Vol.14, $n^{\circ} 1$, jan/abri, 2003.

SOUZA, E. C. de. A arte de contar e trocar experiências: reflexões teórico metodológicas sobre história de vida em formação. Revista Educação em Questão, Natal, v. 25, n. 11, p. 22-39, jan./abr. 2006.

TANCREDI, R. P. Aprendizagem da docência e profissionalização: elementos de uma reflexão. São Carlos: EdUFSCar, 2009.

TARDIF, M.; RAYMOND, D. Saberes, tempo e aprendizagem do trabalho no magistério. Educação \& Sociedade. Campinas: Cedes/Unicamp, v. 21, n. 73, p. 209- 244, dez/ 2000.

TARDIF, M. Saberes docentes e formação profissional. Petrópolis-RJ: Vozes, 2002.

\footnotetext{
i Fundação de Amparo à Pesquisa do Estado de São Paulo. Processo 2016/17830-4.

ii As participantes da pesquisa originária deste artigo são todas mulheres, formadas em Pedagogia e professoras da Educação Infantil.

iii A pesquisa foi aprovada pelo Comitê de Ética em Pesquisa da Instituição de Ensino Superior. Todas as professoras foram devidamente informadas sobre a
} 
pesquisa, concordaram com a participação e assinaram 0 Termo de Consentimento Livre e Esclarecido (TCLE).

iv Apesar de a professora considerar que sua atuação docente teve início com sua formação inicial em razão da forma como realizou o estágio na creche da universidade, optamos por apresentar essas memórias no item "memórias da formação profissional", deste artigo, uma vez que, em razão de não ter a certificação profissional, ela não pode ser considerada de fato como a professora da turma.

Recebido em: 08 de abril de 2019

Aprovado em: 15 de maio de 2019

Publicado em: 17 de agosto de 2020 